\title{
Identification of genomic factors responsible for hybrid lethality in hybrids between Nicotiana nudicaulis Watson and N. tabacum L.
}

\author{
Hongshuo Liu, Wataru Marubashi* \\ Graduate School of Agriculture, Meiji University, Kawasaki, Kanagawa 214-8571, Japan \\ *E-mail: marubasi@isc.meiji.ac.jp Tel \& Fax: +81-44-934-7811
}

Received January 11, 2013; accepted April 14, 2013 (Edited by S. Ogita)

\begin{abstract}
Hybrid lethality was expressed in seedlings from crosses between Nicotiana nudicaulis and N. tabacum at $28^{\circ} \mathrm{C}$. To clarify the subgenome responsible for this phenotype, we crossed $N$. nudicaulis with the two progenitors of $N$. tabacum (SSTT), N. sylvestris (SS) and N. tomentosiformis (TT). Seedlings of N. nudicaulis $\times N$. tomentosiformis did not show any lethal symptoms, and these hybrid seedlings subsequently grew to maturity. On the other hand, in the cross $N$. sylvestris $\times N$. nudicaulis, all seedlings cultured at $28^{\circ} \mathrm{C}$ died immediately after germination, and others cultured at $34^{\circ} \mathrm{C}$ and $36^{\circ} \mathrm{C}$ were nonviable or abnormal; only one hybrid plant survived. These findings suggest that the S subgenome in N. tabacum is responsible for the lethality occurring in hybrids between $N$. nudicaulis and $N$. tabacum. Furthermore, to determine whether the Q chromosome induces this hybrid lethality, we crossed a monosomic line of N. tabacum lacking the Q chromosome with $N$. nudicaulis. Subsequently, we determined the presence or absence of the Q-chromosome-specific DNA marker in hybrid seedlings. Hybrid seedlings both possessing and lacking the Q chromosome showed hybrid lethality when seedlings cultured at $34^{\circ} \mathrm{C}$ were transferred to $28^{\circ} \mathrm{C}$. From these results, we concluded that the $\mathrm{Q}$ chromosome is not responsible for the hybrid lethality observed in crosses of $N$. nudicaulis $\times N$. tabacum.
\end{abstract}

Key words: Hybrid lethality, S subgenome, Q chromosome, N. nudicaulis, N. sylvestris.

Reproductive isolation, which is classified into two types due to prezygotic and postzygotic barriers, is a mechanism playing a crucial role in the evolution of animals and plants (Stebbins 1966). In plant species, hybrid lethality, which can occur in intergeneric, interspecific, and intraspecific crosses, is a potential gene-flow postzygotic barrier. Recently, the mechanism for hybrid lethality observed in Arabidopsis thaliana and lettuce (Lacutca saligna $\times$ L. sativa) was concluded to be an autoimmune-like response due to the interaction between two allelic loci (Bomblies and Weigel 2007; Bomblies et al. 2007; Jeuken et al. 2009).

The genus Nicotiana includes 75 species that are classified into 13 sections distributed in the Americas and Australia and one species ( $N$. africana) that is restricted to Africa (Knapp et al. 2004). In this genus, some interspecific cross combinations exhibit hybrid lethality. The majority of these combinations have been conducted between wild tobacco and well-studied cultivated tobacco, Nicotiana tabacum $(2 n=48$, SSTT), which belongs to section Genuinae. N. tabacum is a natural allotetraploid (amphidiploid) that originated by interspecific hybridization of $N$. sylvestris $(2 n=24$, SS $)$ with $N$. tomentosiformis $(2 n=24, \mathrm{TT})$ and subsequent chromosome doubling (Sheen 1972; Gray et al. 1974; Kenton et al. 1993; Lim et al. 2000; Murad et al. 2002, 2004; Chase et al. 2003; Clarkson et al. 2010). Each chromosome of $N$. tabacum is lettered alphabetically (A to $\mathrm{Z}$, excluding $\mathrm{X}$ and $\mathrm{Y}$ ); chromosomes $\mathrm{A}$ to $\mathrm{L}$ belong to the $\mathrm{T}$ subgenome and $\mathrm{M}$ to $\mathrm{Z}$ to the $\mathrm{S}$ subgenome. A complete set of 24 monosomic lines of $N$. tabacum (Haplo-A to Z) has been established in the genetic background of 'Red Russian' (Clausen and Cameron 1944; Cameron 1959) and is useful for locating genes on specific chromosomes.

In previous studies (Tezuka 2012), monosomic analyses have identified one N. tabacum chromosome that belongs to the S subgenome; in this chromosome, a gene or genes trigger hybrid lethality in crosses between section Suaveolentes and N. tabacum. This hybrid lethality is suppressed at elevated temperatures (32 to $36^{\circ} \mathrm{C}$ ) and induced at $28^{\circ} \mathrm{C}$. Hybrid seedlings from crosses between N. suaveolens and N. tabacum die at $28^{\circ} \mathrm{C}$, but grow normally without exhibiting lethal symptoms at $36^{\circ} \mathrm{C}$ (Manabe et al. 1989). Hybrid seedlings of $N$. suaveolens $\times N$. sylvestris die at $28^{\circ} \mathrm{C}$, but not at $36^{\circ} \mathrm{C}$; hybrid seedlings of $N$. suaveolens $\times N$. tomentosiformis do not exhibit lethality at $28^{\circ} \mathrm{C}$ (Inoue 
et al. 1996). Based on these results, Inoue et al. (1996) found that the S subgenome of $N$. tabacum controls hybrid lethality in these crosses. Moreover, in crosses of a monosomic line of $N$. tabacum lacking the $\mathrm{Q}$ chromosome $($ Haplo- $\mathrm{Q}) \times N$. suaveolens, viable hybrid seedlings were obtained (Marubashi and Onosato 2002).

Tezuka et al. (2004) developed seven Q-chromosomespecific DNA markers. Since one marker, OPC-11 $1_{922}$, was not detected on the $\mathrm{Q}$ chromosome of the cultivar Samsun NN but was detected on the $\mathrm{Q}$ chromosome of Haplo-Q, $\mathrm{F}_{1}$ hybrids of Haplo-Q $\times$ Samsun NN were classified into two groups: monosomic plants without OPC- $11_{922}$ and disomic plants with OPC- $11_{922}$. In these hybrids, the number of monosomic plants was almost the same as disomic plants. Using this approach, Tezuka et al. (2006) carried out crosses of Haplo- $\mathrm{Q} \times N$. suaveolens and found by using four Q-chromosomespecific DNA markers that hybrid seedlings in which Q-chromosome-specific DNA markers were detected expressed hybrid lethality, while hybrid seedlings in which Q-chromosome-specific DNA markers were not detected did not. These results confirmed that the Q chromosome of the $\mathrm{S}$ subgenome is a causal chromosome for hybrid lethality. On the other hand, genes controlling hybrid lethality in the cross $N$. occidentalis $\times N$. tabacum appear in both the $\mathrm{S}$ and $\mathrm{T}$ subgenomes of $N$. tabacum (Tezuka and Marubashi 2012).

Recently, the first linkage map for $N$. tabacum was constructed by Bindler et al. (2011) with SSR markers. Tezuka et al. (2012) used this map and interspecific crosses between $N$. africana and an $N$. tabacum monosomic line lacking the $\mathrm{Q}$ chromosome to determine that linkage group 11 corresponded to the $\mathrm{Q}$ chromosome and that the gene(s) responsible for hybrid lethality mapped to the region of linkage group 11 that included SSR markers PT30342 and PT30365.

Section Repandae exists in North America and consists of four allopolyploid species: $N$. nudicaulis, $N$. repanda, $N$. stocktonii and N. nesophila (Clarkson et al. 2004). In previous studies (Reed and Collins 1978), hybrid lethality was observed in crosses of $N$. repanda $\times N$. tabacum, N. stocktonii $\times N$. tabacum and N. nesophila $\times N$. tabacum. Moreover, crosses between $N$. repanda and $N$. tomentosiformis or $N$. sylvestris were performed to determine which subgenome ( $\mathrm{S}$ or $\mathrm{T}$ ) is responsible for hybrid lethality expressed in the cross $N$. repanda $\times N$. tabacum. Crosses between $N$. repanda and $N$. tomentosiformis resulted in hybrid lethality, but crosses between $N$. repanda and N. sylvestris did not. Based on these results, Kobori and Marubashi (2004) concluded that the $\mathrm{T}$ subgenome included the causative gene(s) for hybrid lethality in this cross.

Nicotiana nudicaulis, which belongs in the section Repandae, is closely related to $N$. repanda (Clarkson et al. 2005 ; 2010). In reciprocal interspecific crosses between
N. nudicaulis and N. tabacum, hybrid lethality was observed at $28^{\circ} \mathrm{C}$, but not at $34^{\circ} \mathrm{C}$ (Yamada et al. 1999; Liu et al. 2013). In this study, we crossed N. nudicaulis with two progenitors of N. tabacum, N. sylvestris (SS) and $N$. tomentosiformis (TT), to reveal which subgenome of $N$. tabacum contains the genomic factors responsible for hybrid lethality in hybrids between $N$. nudicaulis and $N$. tabacum.

\section{Materials and methods}

\section{Plant materials}

The seeds of $N$. nudicaulis Watson $(2 n=48), N$. sylvestris Speg. \& Comes. $(2 n=24, \mathrm{SS})$ and $N$. tomentosiformis Goodsp. $(2 n=24, \mathrm{TT})$ were used in these experiments and were supplied by Japan Tobacco, Inc. (Oyama, Japan). The $N$. tabacum monosomic line Haplo-Q $(2 n=47)$ was supplied by Dr. T. Kubo, Japan Tobacco, Inc. These monosomics were originally produced at the Department of Genetics, University of California, Berkeley (Cameron 1959). Plants were grown and pollinated in the greenhouse of the School of Agriculture, Meiji University.

\section{Interspecific crosses of N. nudicaulis $\times N$. tomentosiformis}

Conventional crossing and sowing were carried out as follows: flowers of $N$. nudicaulis used as maternal parents were emasculated immediately before pollination with pollen of $N$. tomentosiformis. $\mathrm{F}_{1}$ seeds ( $N$. nudicaulis $\times N$. tomentosiformis) were soaked in $0.05 \%$ gibberellic acid $\left(\mathrm{GA}_{3}\right)$ solution for $30 \mathrm{~min}$, sterilized with $5 \%$ sodium hypochlorite for $15 \mathrm{~min}$, and then rinsed three times with sterilized water. Sterilized $\mathrm{F}_{1}$ seeds were sown on Petri dishes containing $8 \mathrm{ml}$ of $1 / 2 \mathrm{MS}$ medium (Murashige and Skoog 1962) supplemented with 1\% sucrose and $0.25 \%$ Gelrite, $\mathrm{pH} 5.8$; the plates were maintained at $28^{\circ} \mathrm{C}$ under continuous illumination $\left(32 \mu \mathrm{mol} \mathrm{s}^{-1} \mathrm{~m}^{-2}\right)$ for seed germination. Immediately after germination, hybrid seedlings were cultured at $28^{\circ} \mathrm{C}$ and $34^{\circ} \mathrm{C}$. At 20 days after germination (DAG), hybrid seedlings cultured at $28^{\circ} \mathrm{C}$ and $34^{\circ} \mathrm{C}$ were all viable. Hybrid seedlings surviving for more than 20 DAG were potted and cultivated in a greenhouse under natural lighting conditions.

\section{Test tube pollination and ovule culture}

Because no fertile seeds were obtained in situ from either the cross $N$. nudicaulis $\times N$. sylvestris or $N$. nudicaulis $\times N$. tabacum monosomic line Haplo- $Q$, test tube pollination and ovule culture, carried out as described by Marubashi and Nakajima (1985), were necessary to obtain hybrid seedlings. Anthers of $N$. nudicaulis were aseptically excised from still-closed flowers and stimulated to dehisce in an incubator $\left(28^{\circ} \mathrm{C}\right)$. Flowers of $N$. sylvestris or Haplo-Q were emasculated 1 day before anthesis; the next day, flowers of N. sylvestris or Haplo-Q were collected and their sepals, petals, and styles were removed. Their ovaries were surface-sterilized with $70 \%$ ethanol for $30 \mathrm{~s}$ 
and then with $5 \%$ sodium hypochlorite for $10 \mathrm{~min}$. The ovary walls were peeled to expose the placenta with intact ovules and then the placentas were placed on $1 / 2$ MS medium with $3 \%$ sucrose. Pollen of $N$. nudicaulis was spread on the surface of the placentas. Pollinated placentas were maintained at $28^{\circ} \mathrm{C}$ under continuous illumination $\left(32 \mu \mathrm{mol} \mathrm{s}{ }^{-1} \mathrm{~m}^{-2}\right)$. Fertilized, enlarged ovules were excised 8 days after test tube pollination and cultured on $1 / 2 \mathrm{MS}$ medium at $28^{\circ} \mathrm{C}$ under continuous illumination $\left(32 \mu \mathrm{mol} \mathrm{s}^{-1} \mathrm{~m}^{-2}\right)$.

\section{Cultivation of hybrid seedlings}

Immediately after germination, hybrid seedlings of $N$. sylvestris $\times N$. nudicaulis were transferred to flat-bottomed test tubes that contained $10 \mathrm{ml}$ of $1 / 2 \mathrm{MS}$ medium supplemented with $1 \%$ sucrose and $0.25 \%$ Gelrite, $\mathrm{pH} 5.8$, and cultured at $28^{\circ} \mathrm{C}, 34^{\circ} \mathrm{C}$, or $36^{\circ} \mathrm{C}$. In a previous report (Liu et al. 2013), the desired results were obtained in a cross of $N$. nudicaulis $\times N$. tabacum at $34^{\circ} \mathrm{C}$. In a preliminary experiment, it was difficult to obtain normal hybrid seedlings of $N$. sylvestris $\times N$. nudicaulis at $34^{\circ} \mathrm{C}$, so the $36^{\circ} \mathrm{C}$ condition was added.

The hybrid seedlings of Haplo-Q $\times N$. nudicaulis were transferred to flat-bottomed test tubes that contained $10 \mathrm{ml}$ of $1 / 2$ MS medium supplemented with $1 \%$ sucrose and $0.25 \%$ Gelrite, $\mathrm{pH} 5.8$, and cultured at $34^{\circ} \mathrm{C}$ immediately after germination. Enlarging seedlings of Haplo- $\times \times N$. nudicaulis were transferred to flat-bottomed test tubes (25$\mathrm{mm}$ diameter, $100-\mathrm{mm}$ length) that contained $10 \mathrm{ml} \mathrm{1/2} \mathrm{MS}$ medium supplemented with $1 \%$ sucrose and $0.25 \%$ Gelrite, pH 5.8, 10 DAG. Seedlings cultured at $34^{\circ} \mathrm{C}$ for $30-40 \mathrm{DAG}$ were then transferred to $28^{\circ} \mathrm{C}$ under continuous illumination ( $32 \mu \mathrm{mol} \mathrm{s}{ }^{-1} \mathrm{~m}^{-2}$ ) to induce hybrid lethality after analysis using Q-chromosome-specific DNA markers.

\section{Random amplified polymorphic DNA (RAPD) analysis and detection of Q-chromosome-specific DNA markers}

Total DNA was extracted from the leaves of the hybrid seedlings using the cetyltrimethylammonium bromide method of Murray and Thompson (1980). RAPD analysis was carried out as described by Williams et al. (1990) using 20 random 10-mer oligonucleotide primers (Kit A; Operon Technologies, Inc., Alameda, CA, USA). The reaction mixture contained $10 \mu$ l SapphireAmp ${ }^{\circledR}$ Fast PCR Master Mix (Takara Bio Inc., Otu, Japan), $0.5 \mu \mathrm{M}$ primer, and $120 \mathrm{ng}$ DNA in a total volume of $20 \mu \mathrm{l}$. PCR amplification was performed using an Applied Biosystems 2720 Thermal Cycler (Applied Biosystems, Foster City, CA, USA) programmed for $3 \mathrm{~min}$ at $94^{\circ} \mathrm{C}$ for initial denaturation, followed by 50 cycles of $30 \mathrm{~s}$ at $94^{\circ} \mathrm{C}, 1 \mathrm{~min}$ at $25^{\circ} \mathrm{C}, 2 \mathrm{~min}$ at $72^{\circ} \mathrm{C}$, and a final extension of $5 \mathrm{~min}$ at $72^{\circ} \mathrm{C}$. PCR products were separated by electrophoresis on $1.5 \%$ agarose gels in TAE buffer and stained with ethidium bromide to visualize DNA bands. The Q-chromosome-specific DNA marker QCS1 was detected as described by Tezuka and Marubashi (2006).
Chromosome analysis of hybrid seedlings from crosses between $N$. nudicaulis and $N$. tomentosiformis

Root tips were pretreated with distilled water for $24 \mathrm{~h}$ at $4^{\circ} \mathrm{C}$ and with $2 \mathrm{mM} 8$-hydroxyquinoline for $4 \mathrm{~h}$ at $4^{\circ} \mathrm{C}$, then fixed in a 3:1 mixture of ethanol and acetic acid overnight to determine chromosome numbers. The root tips were hydrolyzed in $1 \mathrm{~N} \mathrm{HCl}$ for $8 \mathrm{~min}$ at $60^{\circ} \mathrm{C}$, stained with Schiff's reagent and squashed in $45 \%$ acetic acid. The number of chromosomes in at least five root tip cells for each plant was counted under a BX51 light microscope (Olympus, Tokyo, Japan), and photographed using a DP70 automatic photomicrography system (Olympus).

\section{Results}

\section{Viable hybrid seedlings of N. nudicaulis $\times N$. tomentosiformis}

The crosses of $N$. nudicaulis $\times N$. tomentosiformis were carried out via conventional cross-pollination; hybrid seeds were obtained approximately 3 weeks after pollination. Hybrid seeds from $N$. nudicaulis $\times N$. tomentosiformis crosses were sown in $1 / 2 \mathrm{MS}$ medium and germinated at $28^{\circ} \mathrm{C}$. The hybrid seedlings germinated well, and all of the hybrid seedlings were viable at 20 DAG.

Five of the hybrid seedlings were cultivated in a greenhouse and three were randomly selected. All of the selected seedlings grew to maturity and came into flower (Figure 1A). The mature hybrid plants displayed uniform morphological characteristics, with leaf and flower shapes that were intermediate in appearance between those of the parents (Figure 1B-D). Chromosomal analyses of the hybrid plants revealed that each possessed 36 chromosomes, which is the sum of the number of haploid chromosomes of the parents (Figure 1E).

RAPD analysis using the primer OPC-16 was carried out on three hybrid plants to confirm that they were true hybrids (Figure 1F). These plants had several bands characteristic of both parents (arrows); these patterns indicated that they are true hybrids. Similar results, shown in Figure 1F, were also obtained using several other random primers (data not shown). Hybrid plants from the cross $N$. nudicaulis $\times N$. tomentosiformis were sterile.

\section{Nonviable hybrid seedlings of $N$. sylvestris $\times N$. nudicaulis}

When the $N$. nudicaulis $\times N$. sylvestris crosses were carried out via conventional cross-pollination, the diploid seeds of $N$. nudicaulis but no hybrid seeds were obtained. We inferred that fertilization between $N$. nudicaulis and $N$. sylvestris did not occur because of cleistogamy in $N$. nudicaulis. To obtain hybrid seedlings, we carried out crosses of $N$. sylvestris $\times N$. nudicaulis by test tube pollination and ovule culture. Placentas 

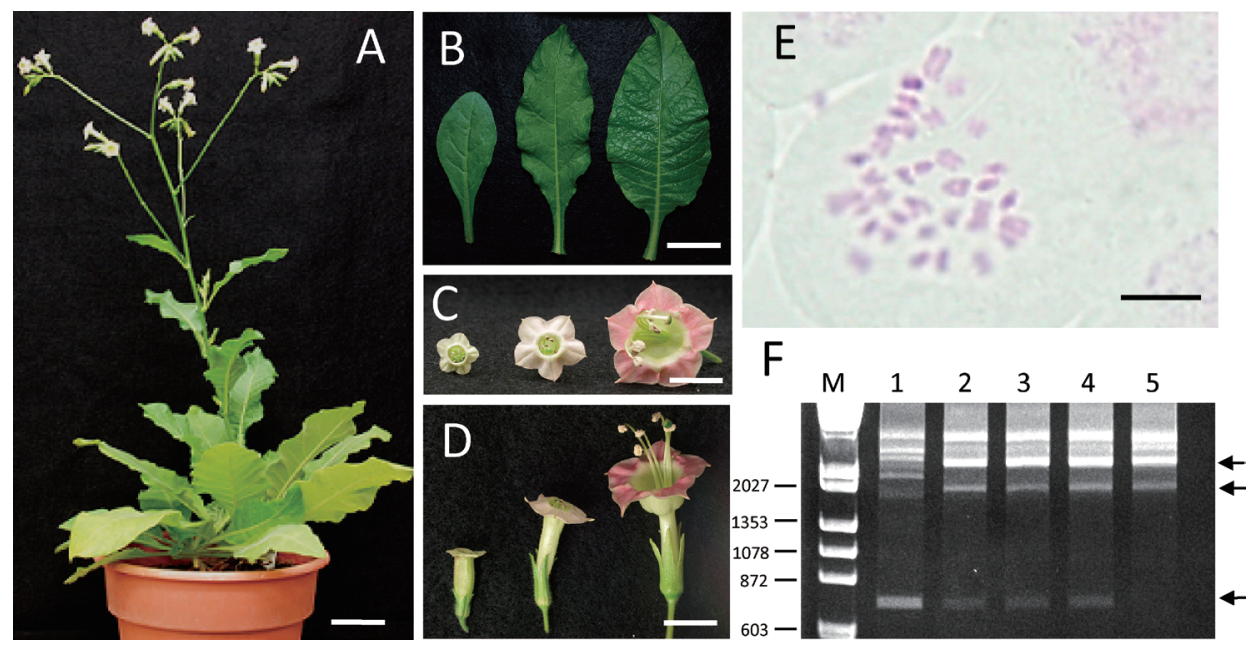

Figure 1. The hybrid of N. nudicaulis $\times$ N. tomentosiformis. (A) Shape of a hybrid plant that has grown to maturity and flowered. (B) Leaves of $N$. nudicaulis, a hybrid and N. tomentosiformis (left to right). (C and D) Flowers of N. nudicaulis, a hybrid and N. tomentosiformis (left to right). (E) Image of root tip cell of a hybrid plant showing the number of chromosomes. (F) Confirmation of hybrid formation by RAPD analysis using primer OPC-16. M: DNA ladder maker ( $\lambda /$ HindIII and $\psi \mathrm{X} 174 /$ HaeIII), Lane 1: N. nudicaulis, Lanes 2-4: hybrid seedlings from a N. nudicaulis $\times N$. tomentosiformis cross, Lane 5: N. tomentosiformis. The bands characteristic of both parents are indicated by arrows. Scale bars are $10 \mathrm{~cm}(\mathrm{~A}), 3 \mathrm{~cm}(\mathrm{~B}), 1 \mathrm{~cm}(\mathrm{C}$ and D) and $100 \mu \mathrm{m}(\mathrm{E})$.
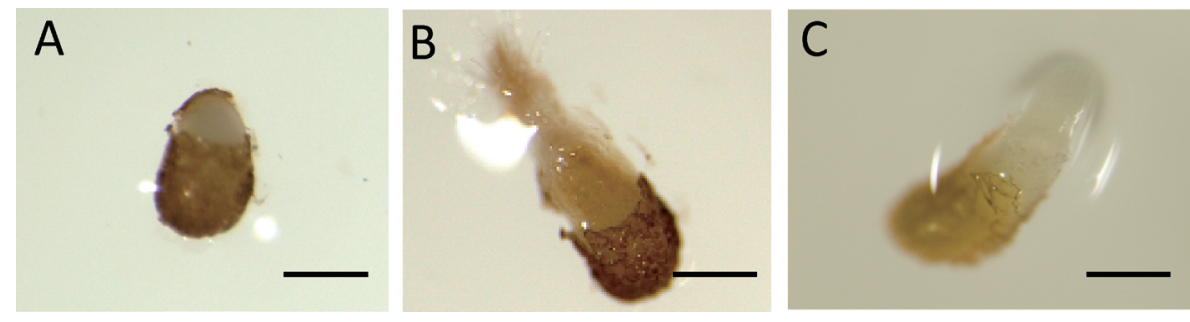

Figure 2. Hybrid seedlings from a N. sylvestris $\times N$. nudicaulis cross cultured at $28^{\circ} \mathrm{C}$. (A) A hybrid seedling without any lethal symptoms immediately after germination. (B) Lethal symptoms observed in hybrid seedlings cultured at $28^{\circ} \mathrm{C}$ for $2 \mathrm{DAG}$. (C) A seedling of N. nudicaulis kept at $28^{\circ} \mathrm{C}$ for 2 DAG. Scale bars are $1 \mathrm{~mm}$.

$(n=563)$ were pollinated. Thereafter, 456 enlarged ovules were obtained 8 days after pollination and 54 of them began to germinate 3 weeks after ovule culture (Table 1). To confirm the expression of hybrid lethality, 20 hybrid seedlings were left at $28^{\circ} \mathrm{C}$ (Table 1); all of these seedlings died within 2 DAG. Symptoms of lethality, including browning of the shoot apex and the root tip, were observed in the hybrid seedlings at an early stage (Figure 2).

To suppress lethality, 17 hybrid seedlings each were transferred to $34^{\circ} \mathrm{C}$ or $36^{\circ} \mathrm{C}$ immediately after germination. Of the 17 hybrid seedlings cultured at $34^{\circ} \mathrm{C}$ (Table 1), only one was viable (Figure $3 \mathrm{~A}$ ); this seedling was cultured at $34^{\circ} \mathrm{C}$ for 3 months after germination and then transferred to $28^{\circ} \mathrm{C}$, where it died 10 days after transfer (Figure 3B). Among the other hybrid seedlings grown at $34^{\circ} \mathrm{C}, 11$ out of 17 were nonviable (Figure $4 \mathrm{~A}$ ) and 4 of the 17 hybrid plants showed vitrification (Figure 4B). One of the 17 hybrid plants was a tumorous hybrid; a tumor developed at the shoot apex of the nonviable plant (Figure 4C). Among the 17 hybrid plants, various changes were observed, including changes from
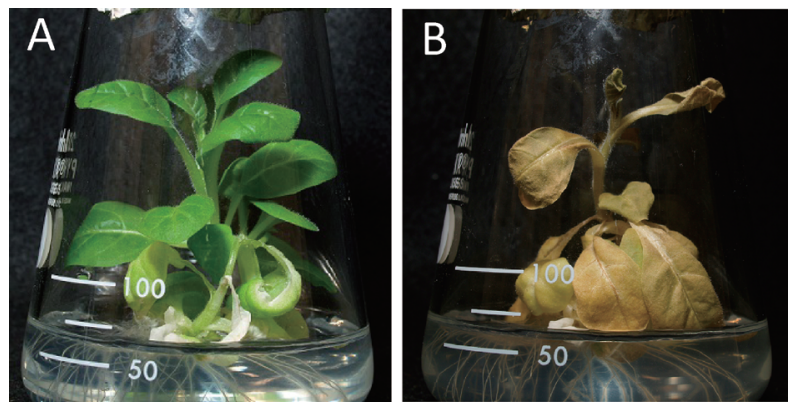

Figure 3. One hybrid plant from a N. sylvestris $\times$. nudicaulis cross that was cultured at $34^{\circ} \mathrm{C}$. A hybrid seedling without any lethal symptoms at $34^{\circ} \mathrm{C}$ for 3 months after germination. (B) Lethal symptoms observed in this hybrid plant after transfer from 34 to $28^{\circ} \mathrm{C}$; it died 10 days after transfer.

tumorous growth to vitrification or death (Figure $4 \mathrm{E}$ and F), and changes from a nonviable hybrid plant to one showing vitrification (Figure 4D).

Of the 17 hybrid seedlings cultured at $36^{\circ} \mathrm{C}$ (Table 1), 10 showed albinism; 4 became albino before the cotyledons developed, and the others began to display 
Table 1. Interspecific hybridization of $N$. sylvestris $\times N$. nudicaulis.

\begin{tabular}{|c|c|c|c|c|c|c|c|c|}
\hline \multirow{2}{*}{ Temperature } & \multirow{2}{*}{$\begin{array}{c}\text { No. of placentas } \\
\text { pollinated }\end{array}$} & \multirow{2}{*}{$\begin{array}{l}\text { No. of ovules } \\
\text { cultured }\end{array}$} & \multicolumn{6}{|c|}{ No. of hybrids obtained } \\
\hline & & & Total & Nonviable & Vitrified & Albino & Tumorous & Viable \\
\hline $28^{\circ} \mathrm{C}$ & 563 & 456 & 20 & 20 & 0 & 0 & 0 & 0 \\
\hline $34^{\circ} \mathrm{C}$ & - & - & 17 & $11\left(1^{\mathrm{a}}\right)$ & $4\left(2^{\mathrm{b}}, 1^{\mathrm{c}}\right)$ & 0 & $1^{\mathrm{d}}$ & 1 \\
\hline $36^{\circ} \mathrm{C}$ & - & - & 17 & 5 & $1^{\mathrm{e}}$ & 10 & $1^{\mathrm{f}}$ & 0 \\
\hline
\end{tabular}

a: A tumorous hybrid plant died within 100 DAG (Figure 4E). b: Vitrification occurred on a tumorous hybrid plants (Figure $4 \mathrm{~F}$ ). c: Vitrification occurred on a nonviable hybrid plant (Figure 4D). d: Tumor developed on a nonviable hybrid plant (Figure 4C). e: Vitrification occurred on a tumorous hybrid plant (Figure 5C). f: Tumor developed on an albino hybrid plant (Figure 5D).

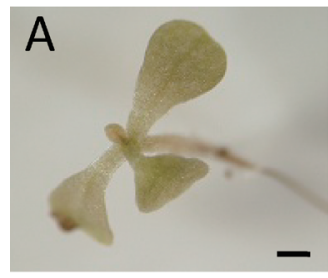

$E$

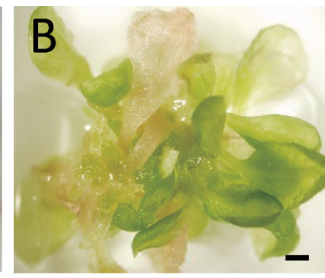

$\mathrm{F}$

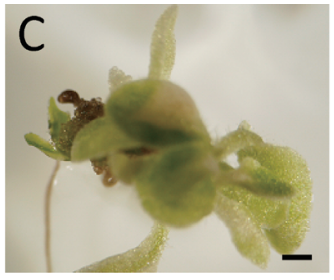

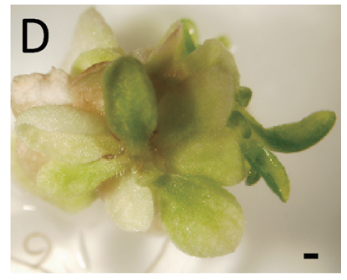

110 DAG
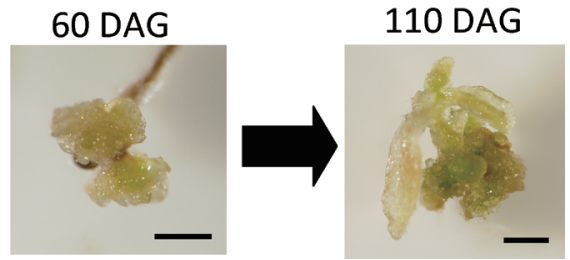

Figure 4. Several types of abnormal hybrid plants from a N. sylvestris $\times N$. nudicaulis cross cultured at $34^{\circ} \mathrm{C}$. (A) A hybrid plant cultured at $34^{\circ} \mathrm{C}$ showing lethal symptoms; it died at 30 DAG. (B) A hybrid plant that showed vitrification. (C) A tumor that developed at the shoot apex of a nonviable hybrid plant. (D) Vitrification that occurred at the shoot apex of a nonviable hybrid plant. (E) A tumorous hybrid plant that died within 100 DAG. (F) Vitrification that occurred on a tumorous hybrid plant. Scale bars are $1 \mathrm{~mm}$.
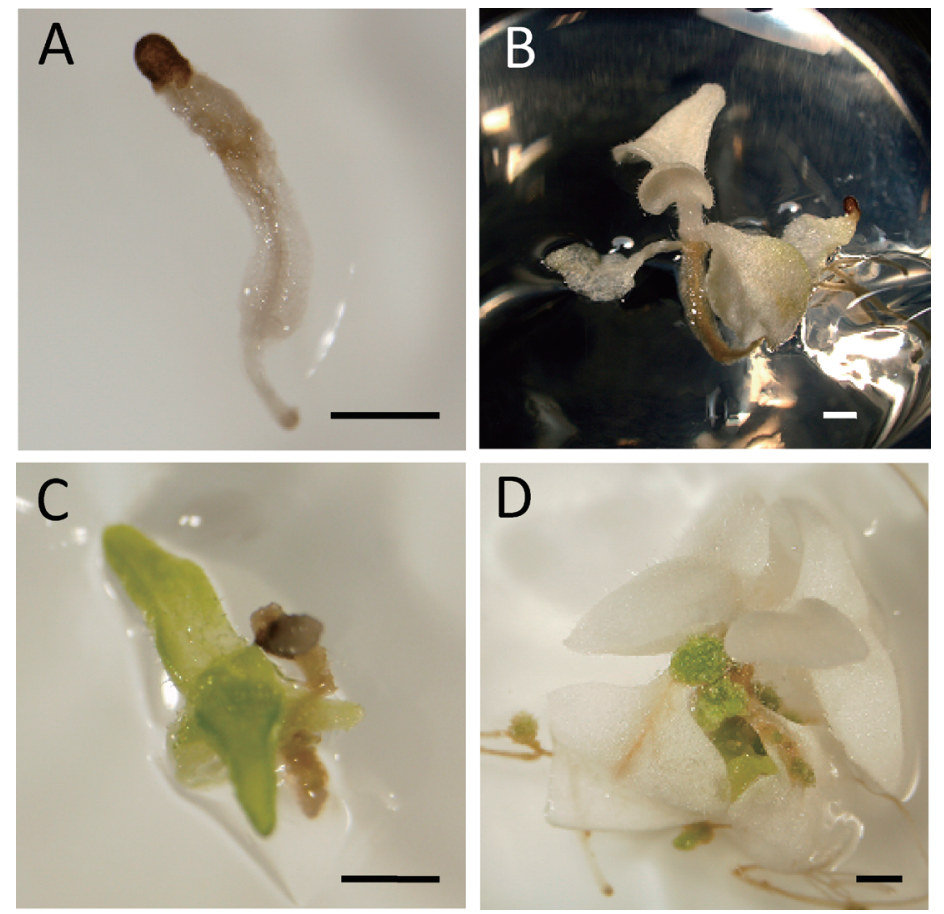

Figure 5. Several types of abnormal hybrid plants from a N. sylvestris $\times N$. nudicaulis cross cultured at $36^{\circ} \mathrm{C}$. (A) A hybrid plant that showed albinism before the cotyledons developed. (B) A hybrid plant that showed albinism after the cotyledons developed. (C) Vitrification occurring on a tumorous hybrid plant. (D) Tumors developing at the shoot apex and the roots of an albino hybrid plant. Scale bars are $1 \mathrm{~mm}$. 
Table 2. Production of hybrid seedlings and phenotypic ratio for the two types ( \pm DNA marker) from the cross of Haplo- $\mathrm{Q} \times N$. nudicaulis.

\begin{tabular}{|c|c|c|c|c|c|c|c|}
\hline \multirow{2}{*}{ Cross combination } & \multirow{2}{*}{$\begin{array}{l}\text { No. of placentas } \\
\text { pollinated }\end{array}$} & \multirow{2}{*}{$\begin{array}{c}\text { No. of ovules } \\
\text { cultured }\end{array}$} & \multirow{2}{*}{$\begin{array}{c}\text { No. of hybrids }{ }^{\mathrm{a}} \\
\text { obtained }\end{array}$} & \multicolumn{2}{|c|}{ DNA marker ${ }^{c}$} & \multirow{2}{*}{$\chi^{2}(1: 1)$} & \multirow{2}{*}{$P$ value } \\
\hline & & & & + & - & & \\
\hline Haplo-Q $\times N$. nudicaulis & 12 & 319 & $70^{\mathrm{b}}$ & 8 & 24 & 8.0 & $0.005-0.001$ \\
\hline
\end{tabular}

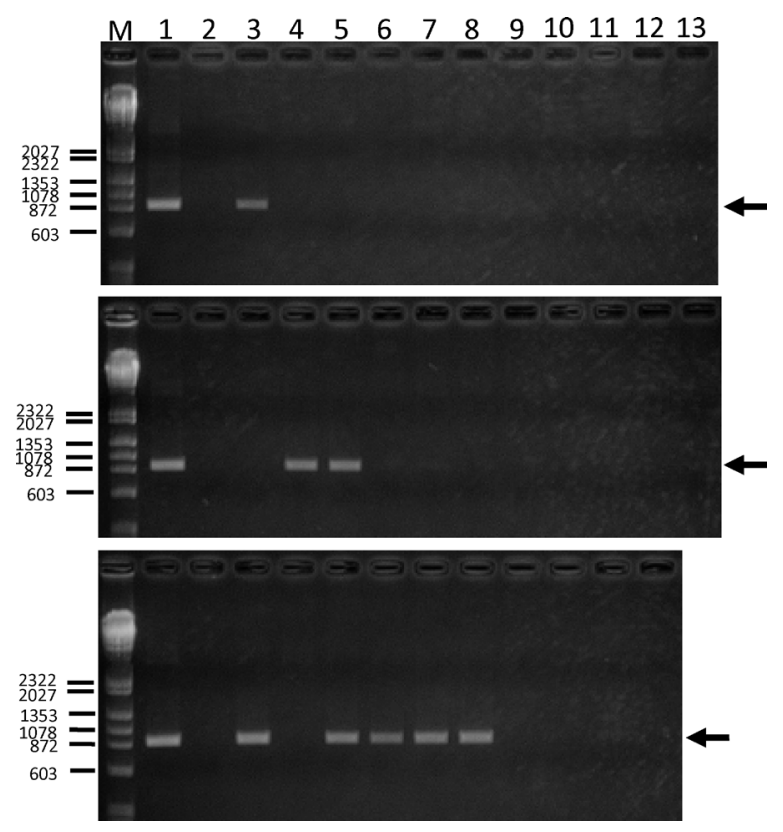

Figure 6. Detection of the marker QCS1 in hybrid seedlings from a Haplo-Q $\times N$. nudicaulis cross. The marker QCS1, indicated by arrows, was detected in hybrid seedlings. M: DNA ladder maker $(\lambda /$ HindIII and భX174/HaeIII), Lane 1: Haplo-Q, Lane 2: N. nudicaulis, Lanes 3-13: hybrid seedlings from a Haplo- $\mathrm{Q} \times N$. nudicaulis cross.

albinism after the cotyledons developed (Figure 5A and B). Five of the 17 hybrid plants were nonviable; lethality symptoms were the same as those exhibited by the nonviable hybrid plants at $34^{\circ} \mathrm{C}$. One of the 17 hybrid plants showed vitrification (Figure 5C) and one hybrid plant was tumorous; tumors developed at the shoot apex and the roots of the albino plant at 70 DAG (Figure 5D).

In this study, all of the hybrid seedlings died at $28^{\circ} \mathrm{C}$; furthermore, half of the hybrid plants were nonviable and only one hybrid plant was viable at $34^{\circ} \mathrm{C}$. At $36^{\circ} \mathrm{C}$, more plants were viable at $34^{\circ} \mathrm{C}$ but most were albino. Based on these results, in $N$. sylvestris $\times N$. nudicaulis crosses, $34^{\circ} \mathrm{C}$ was more effective than $36^{\circ} \mathrm{C}$ for obtaining normal hybrid plants.

\section{Nonviable hybrid seedlings of Haplo- $\mathrm{O} \times \mathrm{N}$. nudicaulis}

N. tabacum monosomic plant lacking the Q chromosome was crossed with $N$. nudicaulis to determine whether the Q chromosome is responsible for hybrid lethality. Since the fertility of pollen of Haplo-Q is very low, the monosomic line was used as a maternal parent. A total

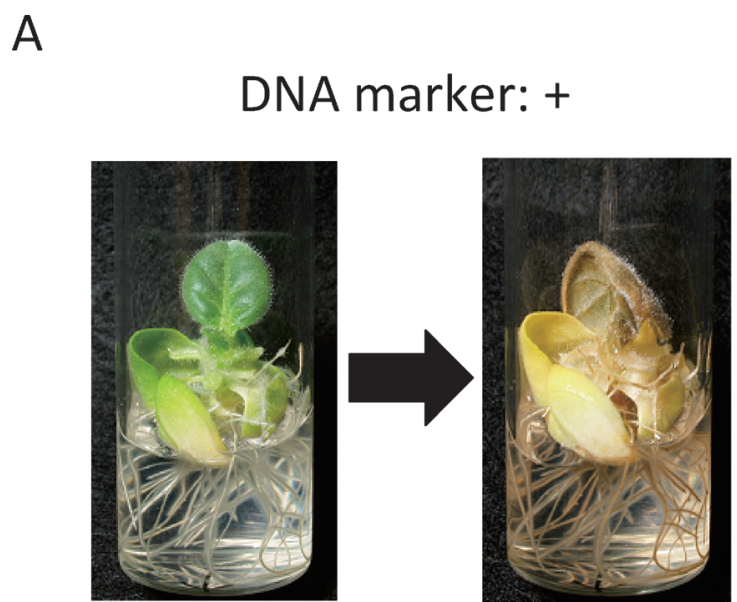

B

\section{DNA marker:-}

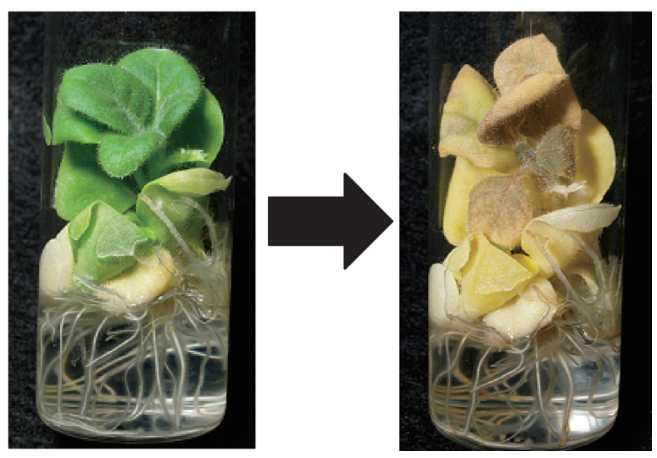

Figure 7. Appearance of hybrid seedlings from a Haplo- $\mathrm{Q} \times$ N. nudicaulis cross after transfer from 34 to $28^{\circ} \mathrm{C}$. Hybrid seedlings were cultured at $34^{\circ} \mathrm{C}$ for $40-50 \mathrm{DAG}$ and then transferred to $28^{\circ} \mathrm{C}$. (A) When a hybrid seedling in which a Q-chromosome-specific DNA marker was detected was transferred to $28^{\circ} \mathrm{C}$, the seedling expressed hybrid lethality and died 10 days after transfer from 34 to $28^{\circ} \mathrm{C}$. (B) When a hybrid seedling in which the Q-chromosome-specific DNA marker was not detected was transferred to $28^{\circ} \mathrm{C}$, the seedling also expressed hybrid lethality and died 10 days after transfer from 34 to $28^{\circ} \mathrm{C}$.

of 12 placentas of Haplo-Q were pollinated in test tubes. Thereafter, 319 enlarged ovules were obtained 8 days later, and 70 began to germinate 3 weeks after ovule culture (Table 2).These hybrid seedlings were then grown at $34^{\circ} \mathrm{C}$, and 32 of them were assessed for the presence or absence of the Q-chromosome using a Q-chromosomespecific DNA marker, QCS1 (Figure 6). Among the hybrid plants, 8 possessed the Q chromosome and 24 
Table 3. Absence of the relationship between the $\mathrm{Q}$ chromosome and hybrid lethality observed in the cross of Haplo- $\mathrm{Q} \times N$. nudicaulis.

\begin{tabular}{ccccc}
\hline \multirow{2}{*}{ Cross combination } & DNA marker & \multicolumn{3}{c}{ No. of hybrids } \\
\cline { 3 - 5 } & & Total & Viable & Nonviable \\
\hline Haplo-Q $\times$ N. nudicaulis & + & 4 & 0 & 4 \\
& - & 6 & 0 & 6 \\
\hline
\end{tabular}

a: The DNA marker used was QCS1 (Tezuka et al. 2004). "+" indicates that the Q-chromosome-specific DNA marker was detected and “-” indicates that it was not.

lacked it (Table 2); the segregation ratio did not fit a $1: 1$ ratio $(p<0.005)$.

Using the Q-chromosome-specific DNA marker, the remaining 10 hybrid seedlings were divided into two types: 4 hybrid seedlings possessing the Q chromosome and 6 hybrid seedlings lacking the $\mathrm{Q}$ chromosome (Table 3). Both types of hybrid seedling were cultured for $40-50$ DAG and then transferred from 34 to $28^{\circ} \mathrm{C}$. Subsequently, 10 days after transfer to $28^{\circ} \mathrm{C}$, both types of seedlings showed lethal symptoms and died (Figure 7A and $\mathrm{B}$ ). These results indicated that the $\mathrm{Q}$ chromosome does not control the lethality of hybrids between $N$. nudicaulis and N. tabacum.

\section{Discussion}

$N$. repanda and $N$. nudicaulis belong to the same section (Leitch et al. 2008). When N. repanda is crossed with the two progenitor species of $N$. tabacum, $N$. sylvestris and $N$. tomentosiformis, hybrid lethality is expressed in seedlings of $N$. repanda $\times N$. tomentosiformis, but not in seedlings of $N$. repanda $\times N$. sylvestris. Based on these results, Kobori and Marubashi (2004) concluded that the $\mathrm{T}$ subgenome is the cause of hybrid lethality occurring in the cross $N$. repanda $\times N$. tabacum. In the present study, we confirmed expression of hybrid lethality in the seedlings of $N$. sylvestris $\times N$. nudicaulis, and not in hybrid seedlings of $N$. nudicaulis $\times N$. tomentosiformis. These results indicate that the $S$ subgenome controls hybrid lethality in $N$. nudicaulis $\times N$. tabacum and clarify that in $N$. nudicaulis and $N$. repanda, different subgenomes ( $\mathrm{S}$ or $\mathrm{T}$ ) interact to lead to hybrid lethality.

In a previous study (Inoue et al. 2000), hybrid lethality was observed and suppressed by high temperature in the cross $N$. suaveolens $\times N$. sylvestris. However, in the cross $N$. sylvestris $\times N$. nudicaulis, hybrid plants were nonviable or abnormal, even at high temperatures $\left(34^{\circ} \mathrm{C}\right.$ and $\left.36^{\circ} \mathrm{C}\right)$. The number of plants obtained was greater at $36^{\circ} \mathrm{C}$ than at $34^{\circ} \mathrm{C}$ but most of them were albino. Based on these results, it is very difficult to obtain normal hybrid plants of $N$. sylvestris $\times N$. nudicaulis. In other words, the hybrid lethality of $N$. sylvestris $\times N$. nudicaulis is very severe. The shape of the hybrid plants of this cross are nonuniform, unlike crosses of wild species (section Suaveolentes) $\times N$. tabacum (Tezuka et al. 2010).

In another study (Tezuka et al. 2004), in hybrid seedlings from the cross Haplo- $\mathrm{Q} \times N$. tabacum $\mathrm{cv}$. Samsun NN, both monosomic and disomic plants were identified using the Q-chromosome-specific DNA marker OPC-11 $1_{922}$, which was not detected in Samsun $\mathrm{NN}(2 n=48)$, but was detected in Haplo-Q. According to this DNA marker, the number of monosomic plants and disomic plants was almost the same. These observations indicate that the absence of the Q chromosome has no effect on the process of embryo sac development or embryogenesis. However, in seedlings of Haplo$\mathrm{Q} \times N$. nudicaulis, the ratio of hybrids possessing the $\mathrm{Q}$ chromosome to hybrids lacking the Q chromosome was $1: 3$. These results indicated that when Haplo-Q is crossed with $N$. nudicaulis, embryogenesis is more favorable for hybrid plants lacking the Q chromosome than for hybrid plants possessing the Q chromosome. We concluded that the Q chromosome might have gene(s) that inhibit embryogenesis when Haplo-Q is crossed with N. nudicaulis.

Marubashi and Onosato (2002) carried out crosses of 10 monosomic lines $(2 n=47$; Haplo-M to $Z$, except for Haplo-P and Haplo-V) of N. tabacum and N. suaveolens. Only when Haplo-Q was crossed with $N$. suaveolens could viable plants be obtained. Furthermore, when Haplo-Q is crossed with $N$. suaveolens and the hybrid seedlings cultured at $36^{\circ} \mathrm{C}$ are transferred to $28^{\circ} \mathrm{C}$, those possessing the $\mathrm{Q}$ chromosome die and those lacking the Q chromosome do not (Tezuka and Marubashi 2006). In the present study, hybrid seedlings both possessing and lacking the $\mathrm{Q}$ chromosome died within 10 days of transfer from 34 to $28^{\circ} \mathrm{C}$. Based on these results, the $\mathrm{Q}$ chromosome is not the cause of hybrid lethality in $N$. nudicaulis $\times N$. tabacum.

In this study, we inferred that both the inhibition of hybrid embryogenesis by the interaction of the $\mathrm{Q}$ chromosome with the genome of $N$. nudicaulis and hybrid lethality in the seedlings due to the interaction of the chromosome(s) of the S subgenome with the genome of $N$. nudicaulis existed in the cross $N$. nudicaulis $\times N$. tabacum. In other words, there are two reproductive barriers acting by different mechanisms in the cross $N$. nudicaulis $\times N$. tabacum. These results suggested that the gene or genes inhibiting hybrid embryogenesis is on the Q chromosome and the gene or genes causing hybrid lethality are on chromosomes other than the Q chromosome. 
Currently, we are attempting to perform crosses of other monosomic lines of $N$. tabacum and $N$. nudicaulis to determine the chromosome of $N$. tabacum that is responsible for hybrid lethality of $N$. nudicaulis $\times N$. tabacum crosses.

\section{Acknowledgements}

We thank Japan Tobacco, Inc. (Oyama, Japan) for providing seeds from cultivated and wild species of the genus Nicotiana and Dr. T. Kubo, former director of the Iwata tobacco experiment station of Japan Tobacco, Inc., for providing tobacco monosomic lines. We are grateful to Dr. N. Kadotani, former Professor at Tamagawa University, for helpful discussions. We are grateful to Dr. T. Yamada, Associate Professor at Tokyo University of Agriculture and Technology, and Dr. T. Tezuka, Assistant Professor at Osaka Prefecture University, for technical advice.

\section{References}

Bindler G, Plieske J, Bakaher N, Gunduz I, Ivanov N (2011) A highdensity genetic map of tobacco (Nicotiana tabacum L.) obtained from large scale microsatellite marker development. Theor Appl Genet 123: 219-230

Bomblies K, Lempe J, Epple P, Warthmann N, Lanz C, Dangl JL, Weigel D (2007) Autoimmune response as a mechanism for a Dobzhansky-Muller-type incompatibility syndrome in plants. PLoS Biol 5: e236

Bomblies K, Weigel D (2007) Hybrid necrosis: autoimmunity as a potential gene-flow barrier in plant species. Nat Rev Genet 8: 382-393

Cameron DR (1959) The monosomics of Nicotiana tabacum. Tob Sci 3: 164-166

Chase MW, Knapp S, Cox AV, Clarkson JJ, Butsko Y, Joseph J, Savolainen V, Parokonny AS (2003) Molecular systematics, GISH and the origin of hybrid taxa in Nicotiana (Solanaceae). Ann Bot (Lond) 92: 107-127

Clarkson JJ, Knapp S, Garcia VF, Olmstead RG, Leitch AR, Chase MW (2004) Phylogenetic relationships in Nicotiana (Solanaceae) inferred from multiple plastid DNA regions. Mol Phylogenet Evol 33: 75-90

Clarkson JJ, Lim KY, Kovarik A, Chase MW, Knapp S, Leitch AR (2005) Long-term genome diploidization in allopolyploid Nicotiana section Repandae (Solanaceae). New Phytol 168: 241-252

Clarkson JJ, Kelly LJ, Leitch AR, Knapp S, Chase MW (2010) Nuclear glutamine synthetase evolution in Nicotiana: phylogenetics and the origins of allotetraploid and homoploid (diploid) hybrids. Mol Phylogenet Evol 55: 99-112

Clausen RE, Cameron DR (1944) Inheritance in Nicotiana tabacum. XVIII. Monosomic analysis. Genetics 29: 447-477

Gerstel DU, Burns JA, Burk LG (1979) Interspecific hybridizations with an African tobacco, Nicotiana africana Merxm. J Hered 70: 342-344

Gray JC, Kung SD, Wildman SG, Sheen SJ (1974) Origin of Nicotiana tabacum L. detected by polypeptide composition of Fraction I protein. Nature (London) 252: 226-227

Inoue E, Marubashi W, Niwa M (1996) Genomic factors controlling the lethality exhibited in the hybrid between Nicotiana suaveolens Lehm. and N. tabacum L. Theor Appl Genet 93: 341-347
Inoue E, Marubashi M, Niwa M (2000) Characterization and overcoming of temperature dependent lethality exhibited in the immature embryo between Nicotiana suaveolens $\times N$. sylvestris. Breed Sci 50: 297-302

Jeuken MJW, Zhang NW, McHale LK, Pelgrom K, den Boer E, Lindhout P, Michelmore RW, Visser RGF, Niks RE (2009) Rin4 causes hybrid necrosis and race-specific resistance in an interspecific lettuce hybrid. Plant Cell 21: 3368-3378

Kenton A, Parokonny AS, Gleba YY, Bennett MD (1993) Characterization of the Nicotiana tabacum L. genome by molecular cytogenetics. Mol Gen Genet 240: 159-169

Knapp S, Chase MW, Clarkson JJ (2004) Nomenclatural changes and a new sectional classification in Nicotiana (Solanaceae). Taxon 53: 73-82

Kobori S, Marubashi W (2004) Programmed cell death detected in interspecific hybrids of Nicotiana repanda $\times N$. tomentosiformis expressing hybrid lethality. Breed Sci 54: 347-350

Leitch IJ, Hanson L, Lim KY, Kovarik A, Chase MW, Clarkson JJ, Leitch AR (2008) The ups and downs of genome size evolution in polyploid species of Nicotiana (Solanaceae). Ann Bot (Lond) 101: 805-814

Liu H, Hoshio M, Masaki Y, Mori Y, Marubashi W (2013) Hybrid lethality with programmed cell death results from reciprocal interspecific crosses between Nicotiana nudicaulis Watson and $N$. tabacum L. Plant Biotechnol 30: 179-184

Lim KY, Matyásek R, Lichtenstein CP, Leitch AR (2000) Molecular cytogenetic analyses and phylogenetic studies in the Nicotiana section Tomentosae. Chromosoma 109: 245-258

Manabe T, Marubashi W, Onozawa Y (1989) Temperaturedependent conditional lethality in interspecific hybrids between Nicotiana suaveolens Lehm. and N. tabacum L. Proc 6th Internatl Congr SABRAO: 459-462

Marubashi W, Nakajima T (1985) Overcoming crossincompatibility between Nicotiana tabacum L. and N. rustica L. by test tube pollination and ovule culture. Jpn J Breed 35: 429-437

Marubashi W, Onosato K (2002) Q chromosome controls the lethality of interspecific hybrids between Nicotiana tabacum and N. suaveolens. Breed Sci 52: 137-142

Murad L, Lim KY, Christopodulou V, Matyasek R, Lichtenstein CP, Kovarik A, Leitch AR (2002) The origin of tobacco's T genome is traced to a particular lineage within Nicotiana tomentosiformis (Solanaceae). Am J Bot 89: 921-928

Murad L, Bielawski JP, Matyasek R, Kovarík A, Nichols RA, Leitch AR, Lichtenstein CP (2004) The origin and evolution of geminivirus-related DNA sequences in Nicotiana. Heredity (Edinb) 92: 352-358

Murashige T, Skoog F (1962) A revised medium for rapid growth and bio assays with tobacco tissue cultures. Physiol Plant 15: 473-497

Murray MG, Thompson WF (1980) Rapid isolation of high molecular weight plant DNA. Nucleic Acids Res 8: 4321-4325

Reed SM, Collins GB (1978) Interspecific hybrids in Nicotiana through in vitro culture of fertilized ovules. J Hered 69: 311-315

Sheen SJ (1972) Isozymic evidence bearing on the origin of Nicotiana tabacum L. Evolution 26: 143-154

Stebbins GL (1966) Reproductive isolation and the origin of species. In: Processes of Organic Evolution. Prentice-Hall, New Jersey, pp 85-112

Tezuka T, Onosato K, Hijishita S, Marubashi W (2004) Development of Q-chromosome-specific DNA markers in tobacco and their use for identification of a tobacco monosomic 
line. Plant Cell Physiol 45: 1863-1869

Tezuka T, Marubashi W (2006) Hybrid lethality in interspecific hybrids between Nicotiana tabacum and N. suaveolens: evidence that the Q chromosome causes hybrid lethality based on Q-chromosome-specific DNA markers. Theor Appl Genet 112: $1172-1178$

Tezuka T, Kuboyama T, Matsuda T, Marubashi W (2010) Seven of eight species in Nicotiana section Suaveolentes have common factors leading to hybrid lethality in crosses with Nicotiana tabacum. Ann Bot (Lond) 106: 267-276

Tezuka T (2012) Hybrid lethality in the genus Nicotiana. In: Mworia JK (ed) Botany. InTech, Janeza Trdine 9, 51000 Rijeka, Croatia 191-210. ISBN 978-953-51-0355-4

Tezuka T, Marubashi W (2012) Genes in S and T subgenomes are responsible for hybrid lethality in interspecific hybrids between Nicotiana tabacum and Nicotiana occidentalis. PLoS ONE 7: e36204. DOI: 10.1371/journal.pone.0036204

Tezuka T, Matsuo C, Iizuka T, Oda M, Marubashi W (2012) Identification of Nicotiana tabacum linkage group corresponding to the Q chromosome gene(s) involved in hybrid lethality. PLoS ONE 7: e37822. DOI: 10.1371/journal.pone.0037822

Williams JGK, Kubelik AR, Livak KJ, Rafalski JA, Tingey SV (1990) DNA polymorphisms amplified by arbitrary primers are useful as genetic markers. Nucleic Acids Res 18: 6531-6535

Yamada T, Marubashi W, Niwa M (1999) Detection of four lethality types in interspecific crosses among Nicotiana species through the use of three rescue methods for lethality. Breed Sci 49: 203-210 